\title{
Glycine binds the transcriptional accessory protein GcvR to disrupt a GcvA/GcvR interaction and allow GcvA-mediated activation of the Escherichia coli gcvTHP operon
}

\author{
Gary Heil, Lorraine T. Stauffer and George V. Stauffer \\ Author for correspondence: George V. Stauffer. Tel: +1 319335 7791. Fax: +1 3193359006. \\ e-mail : george-stauffer@uiowa.edu
}

Department of

Microbiology, The University of lowa, lowa City, IA 52242, USA

\begin{abstract}
The Escherichia coli gcvTHP operon is under control of the LysR-type transcriptional regulator GcvA. GcvA activates the operon in the presence of glycine and represses the operon in its absence. Repression by GcvA is dependent on a second regulatory protein, GcvR. Generally, LysR-type transcriptional regulators bind to specific small co-effector molecules which results in either their altered affinity for specific binding sites on the DNA or altered ability to bend the DNA, resulting in either activation or repression of their respective operons. This study shows that glycine, the co-activator for the gcv operon, does not alter either GcvA's ability to bind DNA nor its ability to bend DNA. Rather, glycine binds to GcvR, disrupting a GcvA/GcvR interaction required for repression and allowing GcvA activation of the gcvTHP operon. Amino acid changes in GcvR that reduce glycine binding result in a loss of glycine-mediated activation in vivo.
\end{abstract}

Keywords: gcvTHP, GcvA, GcvR, glycine, repression

\section{INTRODUCTION}

In Escherichia coli, the primary source of glycine and one-carbon (C1) units is through the serine hydroxymethyltransferase reaction ( $g l y A$ gene product) (Mudd \& Cantoni, 1964). A secondary pathway for the production of $\mathrm{C} 1$ units is the glycine cleavage (GCV) enzyme system, which catalyses the oxidative cleavage of glycine into $\mathrm{CO}_{2}, \mathrm{NH}_{3}$ and a C1 unit (Kikuchi, 1973). The glycine and $\mathrm{C} 1$ units generated by these reactions are not end products, but serve as substrates in other metabolic pathways. Glycine, in addition to its role in protein synthesis, is used as a substrate in the biosynthesis of purines and cell walls (Stauffer, 1996; Blakely, 1969; Jordan \& Sheman, 1972; Pizer \& Potochny, 1964), and C1 units are used in the biosynthesis of purines, thymidine, histidine, coenzyme A and methionine (Matthews, 1996). Methionine, in turn, is converted to $S$-adenosylmethionine, which serves as a

Abbreviations: AP, ampicillin; $\mathrm{C} 1$, one-carbon; co-ppt, co-precipitation gcv, gcvTHP operon; GCV, glycine cleavage; GMS, gel mobility shift; LTTR, LysR-type transcriptional regulator; RNAP, RNA polymerase; TPEG, phenylethyl- $\beta$-D-thiogalactoside. methyl donor for the methylation of proteins and nucleic acids (Mudd \& Cantoni, 1964; Marinus, 1996). The current hypothesis for the physiological role of the GCV enzyme system in E. coli is to balance the requirements of the cell for glycine and C1 units used in these various biosynthetic and methylation reactions.

The GCV enzyme system consists of four proteins designated T-protein, H-protein, P-protein and L-protein (Kikuchi, 1973). The $g c v T, g c v H$ and $g c v P$ genes, encoding the T-, H- and P-proteins, respectively, form an operon at $65.7 \mathrm{~min}$ on the E. coli chromosome (Plamann et al., 1983; Stauffer et al., 1993, 1994). The lpd-encoded lipoamide dehydrogenase, common to the pyruvate and 2-oxoglutarate dehydrogenase enzyme complexes, functions as the L-protein (Steiert et al., 1990). The $l p d$ gene maps at $2 \cdot 8 \mathrm{~min}$ (Berlyn et al., 1996).

Transcription of the $g c v$ operon is under the control of three global regulatory proteins [Lrp, PurR and cAMPreceptor protein $(\mathrm{CRP})]$ and two $g c v$-specific transcriptional regulatory proteins (GcvA and GcvR) (Ghrist \& Stauffer, 1995; Lin et al., 1992; Stauffer \& Stauffer, 1994; Wilson et al., 1993a; Wilson \& Stauffer, 1994; Wonderling \& Stauffer, 1999). Together these 


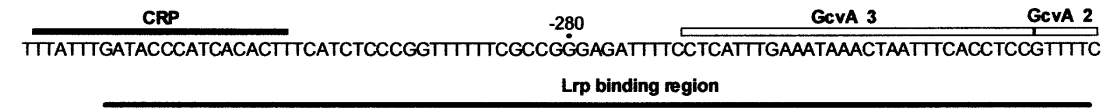

GCATTATATITTCTAATGCCATTATIIITGATITAGTG TIITTGACATIIIITAGCTCTTAATATTGTCTTATTCAAATTTGACTITCT

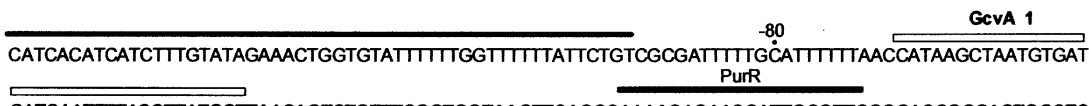

GATCAATTTTACCTTATGGTTAACAGTCTGTTTCGGTGGTAAGTTCAGGCAAAAGAGAACGATTGCGTTGGGGACCGGGAGTGGCTC
Fig. 1. The E. coli gcvTHP control region. The transcription start site $(+1)$, the promoter -10 and -35 regions (Stauffer et al., 1993), and the GcvA (Wilson et al., 1995), Lrp (Stauffer \& Stauffer, 1994), PurR (Wilson et al., 1993a) and CRP (Wonderling \& Stauffer, 1999) binding sites are indicated. proteins modulate transcription of the operon in response to the levels of glycine and purines within the cell.

The leucine-responsive protein (Lrp), a global regulator involved in the control of transcription of several genes involved in amino acid metabolism (Calvo \& Matthews, 1994), binds to multiple sites in the $g c v$ control region from $b p-229$ to -92 relative to the transcriptional start site (Fig. 1) (Stauffer \& Stauffer, 1994). Lrp's role in $g c v$ regulation appears to be structural, binding and bending the DNA to facilitate the formation of the appropriate regulatory complexes for activation or repression of the operon (Stauffer \& Stauffer, 1999), although the possibility that Lrp also activates transcription through interactions with RNA polymerase (RNAP) or a second regulatory protein has not been completely ruled out.

PurR, a repressor for numerous genes involved in nucleotide metabolism (Kilstrup et al., 1989; Rolfes \& Zalkin, 1988), mediates a twofold decrease in $\mathrm{gcv}$ transcription in the presence of exogenous purines (Stauffer et al., 1994; Wilson et al., 1993a). PurR binds to the $g c v$ control region from bp -3 to +17 relative to the transcription start site (Fig. 1) and likely interferes with RNAP binding to the gcv promoter (Wilson et al., 1993a).

CRP binds to a site from approximately bp -303 to -324 relative to the transcription start site (Fig. 1) and is required for a fourfold activation of the $g c v$ operon in glucose minimal (GM) medium (Wonderling \& Stauffer, 1999). The specific mechanism for the observed effect of CRP is unknown. However, the dependence of the CRP effect on the repressor function of GcvA suggests that its role is to antagonize GcvA-mediated repression.

GcvA, a member of the LysR family of transcriptional regulatory proteins, functions as an activator of the $g c v$ operon in the presence of exogenous glycine and as a repressor of the operon in the absence of glycine (Wilson et al., 1993a, b). GcvA-mediated repression is enhanced by the presence of exogenous purines. GcvA binds to three sites in the gcv control region: site 3 from bp -271 to -242 , site 2 from bp -242 to -214 and site 1 from bp -69 to -34 (Fig. 1). All three of these sites are required for repression of the operon, while only sites 2 and 3 appear to be necessary for activation (Wilson et al., 1995; Wonderling et al., 2000). In addition, DNase I footprint studies with GcvA showed hypersensitive cleavage sites in the region between the upstream sites $3+2$ and the downstream site 1 when GcvA was bound to these sites. These results suggest that GcvA might also be involved in bending DNA to form appropriate nucleoprotein complexes at the $g c v$ promoter.

GcvR is necessary for repression of the $g c v$ operon (Ghrist \& Stauffer, 1995). In the absence of GcvR, there is constitutive expression of a $g c v T:$ :lacZ fusion, and overproduction of GcvR results in super-repression of the fusion. Recently, we showed that GcvA and GcvR interact in vivo using a LexA-based two-hybrid system (Ghrist et al., 2001). Since GcvR has no repressor capabilities in the absence of GcvA (Ghrist \& Stauffer, $1995)$, the results suggest that a GcvR/GcvA interaction might be required for repression. Furthermore, since mutations in any of the three GcvA binding sites result in reduced repression (Wilson et al., 1995; Wonderling et al., 2000), at least part of the repression response of the $g c v$ operon likely requires that a GcvR/GcvA repressor complex be bound to gcv DNA.

Most LysR-type transcriptional regulators (LTTRs) are believed to directly bind their specific co-inducer molecules, although in most cases this binding has only been indirectly demonstrated through the isolation of $\mathrm{mu}^{-}$ tants that either no longer respond to their respective coinducer or have altered co-inducer specificity (Colyer \& Kredich, 1996; Jørgensen \& Dandanell, 1999; Schell, 1993). Co-inducer binding by LTTRs is manifested in several ways including altered DNA binding and DNA bending, which facilitate LTTR activation or repression of transcription (Gao \& Gussin, 1991; Wek \& Hatfield, 1988; van Keulen et al., 1998; Ogawa et al., 1999; Hryniewicz \& Kredich, 1994; Wang et al., 1992). How glycine and purines affect GcvA and GcvR to allow an appropriate response at the $g c v$ promoter is unknown. In the present study, we determined the likely role glycine plays as a co-inducer in transcriptional control of the $g c v$ operon. The results suggest that GcvA/GcvR-mediated regulation of $g c v$ utilizes a mechanism that may be unique among LTTR regulated operons.

\section{METHODS}

Strains, plasmids and media. Genotypes of strains and plasmids used are listed in Table 1 . The defined medium used was Vogel \& Bonner minimal salts (Vogel \& Bonner, 1956) supplemented with $0.4 \%$ glucose (GM). GM medium was supplemented with phenylalanine and thiamin since most strains used carry the pheA905 and thi mutations. LuriaBertani broth (LB) and Terrific Broth used for the culturing and overexpression of fusion proteins for purification were 
Table 1. Strains and plasmids used in this study

\begin{tabular}{|c|c|c|}
\hline Strain/plasmid & Relevant genotype & Source \\
\hline \multicolumn{3}{|l|}{ Strains } \\
\hline GS162* & WT & This laboratory \\
\hline GS1054* & $g c v A g c v R$ & This laboratory \\
\hline GS1053* & $g c v R$ & This laboratory \\
\hline GS1089* & $g l y A g c v R$ & This laboratory \\
\hline BL21(DE3) & IPTG-inducible T7 RNAP expressing strain & Stratagene \\
\hline GS1128 & BL21(DE3) derivative, $\Delta g c v R:: \mathrm{KN}^{\mathrm{r}} \dagger$ & This laboratory \\
\hline GS1145 & BL21(DE3) derivative, $\Delta g c v A:: \mathrm{SP}^{\mathrm{r}} \ddagger$ & This study \\
\hline \multicolumn{3}{|l|}{ Plasmids } \\
\hline pBend2 & DNA bending vector & Kim et al. (1989) \\
\hline pET-3d & Multi-copy expression vector; T7 promoter & New England Biolabs \\
\hline pTBY1 & IMPACT expression plasmid & New England Biolabs \\
\hline pGcvR-Impact & $\mathrm{pTBY} 1+g c v R$ & This study \\
\hline pGcvR-R18H-Impact & $\mathrm{pTBY} 1+g c v R \mathrm{R} 18 \mathrm{H}$ & This study \\
\hline pGcvR-L44P-Impact & $\mathrm{pTBY} 1+g c v R L 44 \mathrm{P}$ & This study \\
\hline pGcvR-F50S-Impact & pTBY $1+g c v R F 50 S$ & This study \\
\hline pGcvR-T130M-Impact & $\mathrm{pTBY} 1+g c v R T 130 \mathrm{M}$ & This study \\
\hline pGS311 & Single-copy plasmid & This laboratory \\
\hline pGS338 & Single-copy plasmid + WT gcvR allele & This laboratory \\
\hline pGS558 & Single-copy plasmid $+g c v R \mathrm{R} 18 \mathrm{H}$ allele & This study \\
\hline pGS559 & Single-copy plasmid $+g c v R L 44 \mathrm{P}$ allele & This study \\
\hline pGS560 & Single-copy plasmid $+g c v R F 50$ S allele & This study \\
\hline pGS589 & Single-copy plasmid $+g c v R T 130 \mathrm{M}$ allele & This study \\
\hline pGS318 & Multi-copy plasmid $+g c v T:: l a c Z$ fusion & Stauffer \& Stauffer (1998b) \\
\hline pGS357 & Multi-copy plasmid $+g c v T$ : : lacZ fusion with 4 bp changes in GcvA site 1 & Wilson et al. (1995) \\
\hline pGS420 & pGS318 with 15 bp insert between GcvA binding sites $3+2$ and site 1 & Stauffer \& Stauffer (1998b) \\
\hline pGS428 & pGS318 with 25 bp insert between GcvA binding sites $3+2$ and site 1 & Stauffer \& Stauffer (1998b) \\
\hline pGS473 & Multi-copy plasmid; IPTG-inducible $g c v A_{6 \times h i s}$ allele & Jourdan \& Stauffer (1999) \\
\hline pGS498 & pET-3d; T7 promoter-controlled $g c v A_{6 \times \text { his }}$ allele & This study \\
\hline
\end{tabular}

* These strains also carry thi, pheA905, AlacU169, araD129 and rpsL150 mutations.

† KN, kanamycin.

$\ddagger$ SP, spectinomycin.

prepared as described by Sambrook et al. (1989). Supplements were added where indicated at the following concentrations: ampicillin (AP), $200 \mu \mathrm{g} \mathrm{ml}^{-1}$ for the maintenance of multicopy expression vectors and $50 \mu \mathrm{g} \mathrm{ml}^{-1}$ for the maintenance of single-copy plasmids; tetracycline, $10 \mu \mathrm{g} \mathrm{ml}^{-1}$; inosine, $50 \mu \mathrm{g} \mathrm{ml}^{-1}$; X-gal, $40 \mu \mathrm{g} \mathrm{ml}^{-1}$; phenylethyl- $\beta$-D-thiogalactoside (TPEG), $2 \mathrm{mM}$; IPTG, $600 \mu \mathrm{M}$.

Enzyme assays. $\beta$-Galactosidase assays were performed on mid-exponential phase cells $\left(\mathrm{OD}_{600} \sim 0.5\right)$ as described by Miller (1992) using the chloroform/SDS lysis procedure. All results are the means of two or more assays, with each sample done in triplicate. Standard deviations for each data point were within $15 \%$ of the mean.

Protein purification. Plasmid pGS473 carries gcvA on an EcoRI-HindIII fragment (Jourdan \& Stauffer, 1999). In this construct $g c v A$ is under transcriptional control of the inducible lac promoter, contains an artificial Shine-Dalgarno sequence and has six histidine codons at the $3^{\prime}$ end of the gcvA ORF. pGS473, however, did not express the hexa-histidine-tagged GcvA ( $\left.\operatorname{GcvA}_{6 \times \text { his }}\right)$ to levels sufficient for use in this work. To increase levels of $\mathrm{GcvA}_{6 \times \text { his }}$ we constructed pGS498 as follows. pGS473 was digested with EcoRI, the ends filled using the large fragment of DNA polymerase I and XbaI linkers added. The resulting fragment was then digested with $\mathrm{XbaI} / \mathrm{HindIII}$, the fragment gel-purified and ligated into the corresponding sites in the pET-3d vector (New England Biolabs), placing the $g c v A_{6 \times \text { his }}$ allele under transcriptional control of the T7 promoter. Since GcvA and GcvR interact in vivo (Ghrist et al., 2001), pGS498 was used to transform the $\Delta g c v R:: \mathrm{KN}^{\mathrm{r}}$ strain GS1128 on LB agar + AP, and an $\mathrm{AP}^{\mathrm{r}}$ transformant isolated. Expression of $\mathrm{GcvA}_{6 \times \text { his }}$ in strain GS1128 prevents the possible co-purification of GcvA $\mathrm{G}_{6 \times \text { nis }}$ and WT GcvR. The APr transformant was used to inoculate $3 \mathrm{ml}$ Terrific Broth $+\mathrm{AP}$ and the culture was incubated at $37^{\circ} \mathrm{C}$ for $3 \mathrm{~h}$. To prevent the accumulation of $\beta$-lactamase in the growth medium that could result in the loss of the expression plasmid from cells and lower protein expression, cells from the $3 \mathrm{ml}$ culture were harvested by centrifugation and used to inoculate 11 Terrific Broth $+\mathrm{AP}$. The culture was grown at $30^{\circ} \mathrm{C}$ to $\mathrm{OD}_{600}$ between $1 \cdot 2$ and 1.4 . Expression of the T7 RNAP was induced by the addition of IPTG, resulting in transcription of $g c v A_{6 \times \text { his }}$. Induced cultures were then incubated at $24^{\circ} \mathrm{C}$ for $7 \mathrm{~h}$, the cells harvested by centrifugation, resuspended in loading buffer $\mathrm{A}$ (50 mM HEPES/ NaOH pH 7•4, 500 mM NaCl, 1 mM EDTA, $0 \cdot 1 \%$ Triton X-100) and sonicated. The lysate was clarified by 

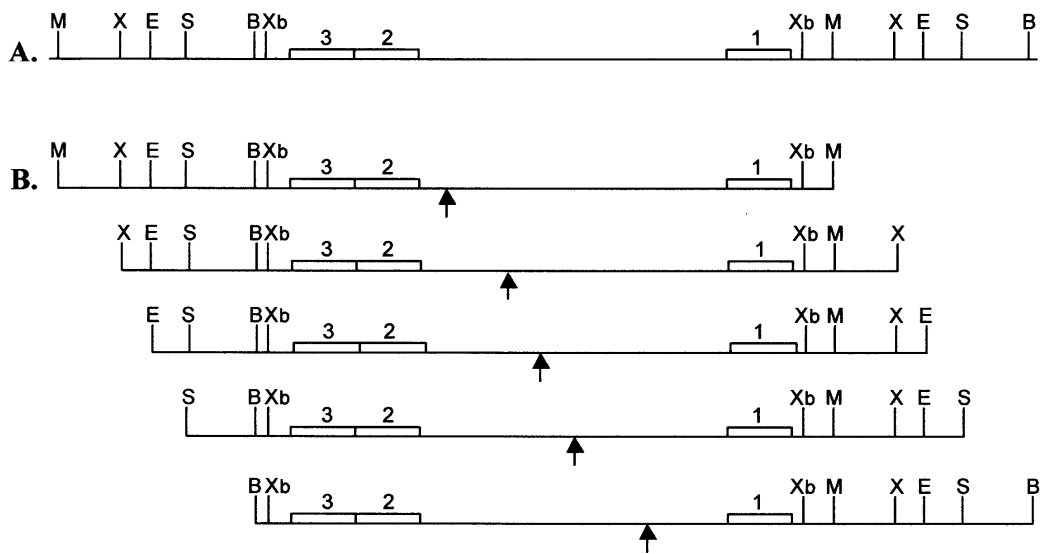

\begin{abstract}
Fig. 2. A. Location of the $X$ bal fragment carrying the GcvA binding sites $3+2+1$ cloned into the $X b a l$ site of plasmid pBend2. $B$. Location of the GcvA binding sites in the 365 bp Mlul, Xhol, EcoRV, Stul and BamHI fragments. M, Mlul; X, Xhol; E, EcoRV; S, Stul; B, BamHI; Xb, Xbal. The centre of each fragment is indicated with an arrow. Only relevant restriction enzyme sites are shown.
\end{abstract}

centrifuging at 12000 r.p.m. in a Sorvall SS-34 rotor for $30 \mathrm{~min}$ at $4{ }^{\circ} \mathrm{C}$, followed by centrifugation at 40000 r.p.m. in a Beckman $60 \mathrm{Ti}$ rotor for $1 \mathrm{~h}$ at $4{ }^{\circ} \mathrm{C}$. Solid ammonium sulfate was added to $33 \%$ saturation and incubated further at $4{ }^{\circ} \mathrm{C}$ for $2 \mathrm{~h}$. The precipitate was recovered by centrifugation, dissolved in $5 \mathrm{ml}$ loading buffer $\mathrm{A}$ and loaded onto a $5 \mathrm{ml} \mathrm{Hi}$ Trap metal chelating column (Pharmacia Biotech) pre-equilibrated with loading buffer A. The column was washed with 20 vols loading buffer A followed by 10 column vols wash buffer A (50 mM HEPES/NaOH pH 7•4, $500 \mathrm{mM} \mathrm{NaCl}$, $0 \cdot 1 \mathrm{mM}$ EDTA, $10 \%$ glycerol, $20 \mathrm{mM}$ imidazole). GcvA ${ }_{6 \times h i s}$ protein was then eluted from the column with a $20-500 \mathrm{mM}$ gradient of imidazole in wash buffer A. GcvA $6 \times$ his eluted from the column at approximately $125 \mathrm{mM}$ imidazole. Fractions containing GcvA were pooled, concentrated using an Amicon membrane ultrafiltration system with a 10000 molecular mass cut off and stored at $4{ }^{\circ} \mathrm{C}$ in wash buffer $\mathrm{A}+125 \mathrm{mM}$ imidazole.

The $g c v R$ ORF was cloned into the vector pTBY1 of the Impact I protein purification system (New England Biolabs) as follows. The $g c v R$ ORF carried on pBR322 was PCR amplified using a $5^{\prime}$ primer that encoded an $\mathrm{XbaI}$ restriction site, the Shine-Dalgarno sequence from the E. coli rpoA gene and the first six codons of the $g c v R$ ORF, and a 3 ' primer that encoded the last six codons of the $g c v R$ ORF in-frame with the first six codons of the intein autocatalytic cleavage signal (which contains a natural KpnI restriction site). The PCR product and pTBY1 vector were digested with $X b a \mathrm{I} / K p n \mathrm{I}$, the appropriate DNA fragments were purified from a $1 \%$ agarose gel, and ligated. The products of the ligation were used to transform the $\Delta g c v A:: \mathrm{SP}^{\mathrm{r}}$ strain GS1145 to prevent co-purification of GcvR and WT GcvA, and transformants selected on LB agar $+\mathrm{AP}$. One $\mathrm{AP}^{\mathrm{r}}$ transformant was single-colony purified and grown in LB + AP, plasmid DNA was isolated and the presence of the PCR product confirmed by digestion with $X b a \mathrm{I} / K p n \mathrm{I}$. DNA sequencing of the plasmid using the T7 forward and intein reverse primers (New England Biolabs) confirmed that the GcvR-intein reading frame was maintained. This plasmid, designated pGcvR-Impact, was the parent vector used to construct mutant $g c v R$ expression vectors as follows. Mutant $g c v R$ alleles were PCR amplified as described above and cloned into the $\mathrm{XbaI} / \mathrm{KpnI}$ restriction sites of pGcvR-Impact.

Growth of strain GS1145 carrying pGcvR-Impact (or mutated $g c v R$ alleles), induction of the GcvR:: intein::chitin binding domain fusion, and preparation of the cleared lysate were performed as described above for $\mathrm{GcvA}_{6 \times \text { his }}$ except that loading buffer B contained $20 \mathrm{mM}$ HEPES/ $\mathrm{NaOH}$ pH 7·4, $500 \mathrm{mM} \mathrm{NaCl}, 1 \mathrm{mM}$ EDTA, $0 \cdot 1 \%$ Triton X-100. The cleared

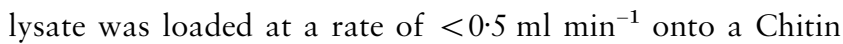
affinity matrix column (New England Biolabs) pre-equilibrated with loading buffer B, washed with 25 column vols loading buffer B followed by 10 column vols wash/elution buffer (20 mM HEPES, pH 7.4, $150 \mathrm{mM} \mathrm{NaCl,} 0 \cdot 1 \mathrm{mM}$ EDTA, $10 \%$ glycerol). The column was then washed with 3 column vols wash/elution buffer containing $30 \mathrm{mM}$ DTT, and the column left static overnight at $4{ }^{\circ} \mathrm{C}$ to allow cleavage of the intein moiety of the fusion. Native GcvR protein was eluted from the column with wash/elution buffer and stored at $4{ }^{\circ} \mathrm{C}$.

Gel mobility shift (GMS) and DNA bending assays. GMS assays were performed as described (Fried \& Crothers, 1981; Garner \& Revzin, 1981). DNA fragments were prepared as follows. Plasmid pGS318 carries an in-frame gcv T::lacZ fusion (Stauffer \& Stauffer, 1998a). Plasmids pGS420 and pGS428 were derived from pGS318 and carry a 15 bp and a 25 bp insert between GcvA binding site $3+2$ and site 1, respectively (Stauffer \& Stauffer, 1998b). Plasmid pGS357 has a 4 bp change in site 1 that reduces GcvA binding to site 1 about twofold (Wilson et al., 1995; Wonderling et al., 2000). These plasmids were used as the starting templates in PCR reactions with primers containing $\mathrm{XbaI}$ sites and sequences complementary to $g c v$ upstream and downstream the GcvA binding sites. The resulting 244, 259 and $264 \mathrm{bp}$ DNA fragments generated from pGS318, pGS420 and pGS428, respectively, carry GcvA binding sites $3+2+1$, and were cloned into the $\mathrm{XbaI}$ site of plasmid pBend2. Five different restriction enzymes were then used to generate DNA fragments of identical length $(365 \mathrm{bp})$, but with different locations of the GcvA binding sites (Fig. 2). The fragments were ${ }^{32} \mathrm{P}$ labelled at their $5^{\prime}$ termini with T4 polynucleotide kinase (Sambrook et al., 1989). Target DNA was added to $20 \mu \mathrm{l}$ reaction mixtures containing DNA binding buffer $(10 \mathrm{mM}$ Tris $/ \mathrm{HCl} \mathrm{pH} \mathrm{7.5,} 50 \mathrm{mM} \mathrm{KCl,} \mathrm{0.5} \mathrm{mM} \mathrm{EDTA,} 5 \%$ glycerol,

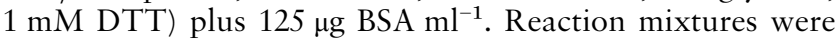
pre-incubated for $5 \mathrm{~min}$ at $37^{\circ} \mathrm{C}, 2 \mu \mathrm{l}$ purified $\mathrm{GcvA}_{6 \times \text { his }}$ was added at the concentrations indicated in Figs 3 and 5 , and incubation continued for $15 \mathrm{~min}$. One microlitre of loading dye $(0.1 \%$ xylene cyanol and $50 \%$ glycerol in water $)$ was added to each reaction mixture and the samples were loaded onto a $5 \%$ polyacrylamide gel and run at $12 \mathrm{~V} \mathrm{~cm}^{-1}$. Gels were transferred to $3 \mathrm{MM}$ Whatman paper, dried and autoradiographed. DNA bending by $\mathrm{GcvA}_{6 \times \text { his }}$ was calculated as described by Kim et al. (1989).

Co-precipitation (co-ppt) experiments. The following buffers were used in the GcvA/GcvR affinity co-ppt experiments: loading buffer C (20 mM HEPES/NaOH pH 7.4, $150 \mathrm{mM}$ $\mathrm{NaCl}, 0 \cdot 1 \mathrm{mM}$ EDTA, $10 \%$ glycerol), wash buffer B (loading 
(a)

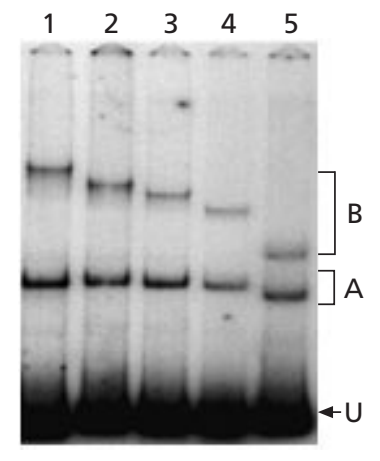

(b)

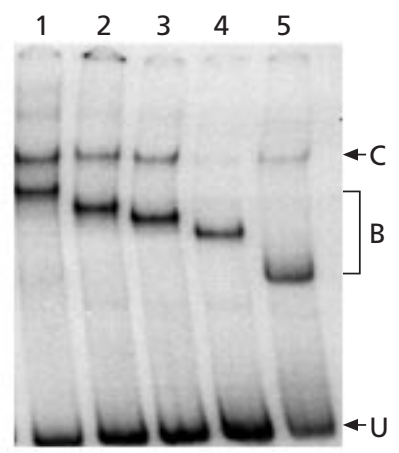

Fig. 3. GcvA binding to the $g c v$ control region induces DNA bending. Five ${ }^{32} \mathrm{P}$-labelled DNA fragments of identical length were prepared with the GcvA binding sites at various locations (see Fig. 2). Lanes: 1, Mlul fragment; 2, Xhol fragment; 3, EcoRV fragment; 4, Stul fragment; 5, BamHI fragment. GcvA was added at a dimer concentration of $4.5 \mathrm{nM}$ (a) or $18 \mathrm{nM}$ (b). The positions of the unbound $(U)$ and three GcvA-retarded bands $(A, B$ and $C)$ are indicated.

buffer $\mathrm{C}+20 \mathrm{mM}$ imidazole, $\mathrm{pH}$ adjusted to $7 \cdot 4$ after addition of imidazole) and elution buffer (loading buffer C $+500 \mathrm{mM}$ imidazole, $\mathrm{pH}$ adjusted to $7 \cdot 4$ after addition of imidazole). Glycine was added to the loading and wash buffers where indicated at $1 \mathrm{mM}$.

$\mathrm{Ni}^{+}$-NTA agarose affinity matrix (Qiagen) was dispensed into $30 \mu \mathrm{l}$ aliquots for each co-ppt and washed twice with $400 \mu \mathrm{l}$ loading buffer $\mathrm{C}$ to equilibrate, each time briefly centrifuging and decanting the supernatant with a Pasteur pipette. GcvA $6 \times$ nis ('bait') was diluted to $50 \mu \mathrm{g} \mathrm{ml}^{-1}$ in $200 \mu \mathrm{l}$ loading buffer $\mathrm{C}$, added to $30 \mu \mathrm{l}$ affinity matrix and incubated with gentle mixing at $20^{\circ} \mathrm{C}$ for $15 \mathrm{~min}$. The affinity matrix was collected by centrifugation as above and the supernatant saved as sample 1 . The $\mathrm{Ni}^{+}$-NTA agarose was washed twice with $200 \mu \mathrm{l}$ loading buffer $\mathrm{C}$ to remove unbound protein. Following each of the washes the $\mathrm{Ni}^{+}$-NTA agarose was centrifuged, and the supernatants decanted and saved as samples 2 and 3. GcvR ('target') was diluted to $50 \mu \mathrm{g} \mathrm{ml}^{-1}$ in $200 \mu \mathrm{l}$ loading buffer C and added to the $\mathrm{Ni}^{+}$-NTA agarose-GcvA 6 incubation continued at $20^{\circ} \mathrm{C}$ for $15 \mathrm{~min}$. The affinity matrix was collected by centrifugation and the supernatant saved as sample 4. The matrix was then washed twice with $200 \mu \mathrm{l}$ loading buffer $\mathrm{C}$ to remove unbound target protein. Following each of the washes the $\mathrm{Ni}^{+}$-NTA agarose was centrifuged, the supernatants decanted and saved as samples 5 and 6 . The $\mathrm{Ni}^{+}$NTA agarose-protein complex was washed twice with $200 \mu \mathrm{l}$ wash buffer $\mathrm{B}$ to remove target protein non-specifically bound to the matrix. Each wash was incubated for $5 \mathrm{~min}$ at $20^{\circ} \mathrm{C}$ with gentle mixing, the mixtures centrifuged, and the supernatants collected as samples 7 and 8 . The $\mathrm{Ni}^{+}$-NTA agaroseprotein complex was then washed twice with $200 \mu$ l elution buffer. Each wash was incubated for $5 \mathrm{~min}$ at $20^{\circ} \mathrm{C}$ with gentle mixing, the $\mathrm{Ni}^{+}$-NTA agarose was collected by centrifugation, and the supernatants collected and combined as sample 9. Four volumes of acetone were added to each sample, the proteins precipitated on ice for $30 \mathrm{~min}$, and pelleted by centrifugation at 14000 r.p.m. [16000 $g$ in a refrigerated $\left(4^{\circ} \mathrm{C}\right)$ Eppendorf microfuge]. The supernatants were decanted and the proteins dried under vacuum. The protein samples were resuspended in SDS loading buffer, heated at $95^{\circ} \mathrm{C}$ for $5 \mathrm{~min}$ and loaded onto a $10 \%$ polyacrylamide/SDS gel.
Equilibrium dialysis. Equilibrium dialysis was conducted using a micro-chamber equilibrium dialysis apparatus with pairs of $100 \mu \mathrm{l}$ chambers separated by a 12000-14000 molecular mass cut off Spectrapor dialysis membrane (Spectrum Medical Industries). Each protein tested was diluted to $25 \mu \mathrm{M}$ in dialysis buffer (20 mM HEPES/ $\mathrm{NaOH}$ pH 7•4, $150 \mathrm{mM} \mathrm{NaCl}$, $0 \cdot 1 \mathrm{mM}$ EDTA, $10 \%$ glycerol) and placed in chambers (inside) opposite chambers containing $\left[{ }^{14} \mathrm{C}\right]$ glycine $(\sim 16500$ c.p.m.) in dialysis buffer (outside). Following overnight mixing of the dialysis cells at $20^{\circ} \mathrm{C}, 50 \mu \mathrm{l}$ samples from each chamber on opposite sides of the membrane were collected. The amount of $\left[{ }^{14} \mathrm{C}\right]$ glycine in each of the samples was determined by counting the samples in $10 \mathrm{ml}$ Budget-Solve scintillation cocktail (Research Products International). The amount of $\left[{ }^{14} \mathrm{C}\right]$ glycine bound was determined by subtracting the counts 'outside' from the counts 'inside' each pair of chambers (Miller, 1992).

Random mutagenesis. Mutagenesis of $g c v R$ was performed using a PCR mutagenesis protocol (Zhou et al., 1991). PCR products were generated using primers complementary to the DNA template outside of the $g c v R$ gene and overlapping an EcoRI restriction site at the $5^{\prime}$ end and a HindIII site at the 3' end. The PCR products were digested with EcoRI/HindIII, cloned into plasmid pBR322 and used to transform the gcvA mutant lysogen GS998igcv T: : lacZ carrying the gcvAR197G allele on the single-copy plasmid pGS311. The gcvAR197G allele results in constitutive expression of the $g c v$ operon (Jourdan \& Stauffer, 1998). Transformants were selected on LB agar containing AP + TC to maintain both plasmids. Transformants were spotted onto GM agar supplemented with inosine, AP, TC, X-gal and TPEG. TPEG is a competitive inhibitor of $\beta$-galactosidase and increases the stringency of the selection. When WT $g c v A$ is carried on the single-copy plasmid and WT $g c v R$ is carried on the multi-copy plasmid, colonies are white due to low levels of expression of the gcv $T:: l a c Z$ fusion. Alternatively, when the gcvAR197G allele was expressed from the single-copy plasmid along with the WT gcvR allele on the multi-copy plasmid, colonies were blue due to high levels of expression of the gcvT::lacZ fusion. We assumed that mutations in $g c v R$ that restore repression in the presence of the gcvAR197G allele would be less blue. Thus, light blue colonies, presumably with increased repression of gcv $T$ : : lacZ, were saved for further analysis.

\section{RESULTS}

\section{Effects of glycine on GcvA binding to the gcv control region and bending DNA}

Most LTTRs have been shown to bind to their promoters in the absence of their respective co-inducers (Schell, 1993). The presence of the co-inducer molecule usually results in either an altered DNA binding affinity of the LTTR, observed as an increase in the number of protein monomers bound to a specific site, or altered DNA bending of the promoter region by the LTTR (Gao \& Gussin, 1991; Wek \& Hatfield, 1988; Ogawa et al., 1999; Rhee et al., 1998; van Keulen et al., 1998). These effects result in appropriate transcriptional regulation of the respective operons. Previous DNase I protection studies using crude extracts containing overexpressed GcvA did not show alterations in the degree of protection or in the pattern of protection of the $\mathrm{gcv}$ control region upon the addition of glycine (Wilson et al., 1995), and previous GMS experiments were con- 


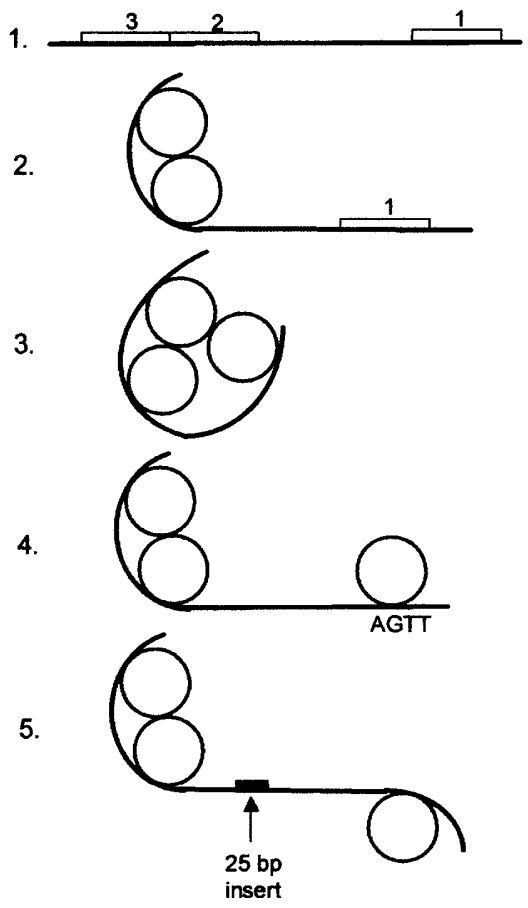

Fig. 4. One interpretation of the GMS assays. For simplicity, GcvA is shown as a circle, although biophysical experiments show it exists as a tetramer in solution (G. Heil, G. V. Stauffer and A. Robertson, unpublished). A 25 bp insertion is indicated as a thick bar. 1. Positions of the three GcvA binding sites. 2. Binding of GcvA to sites $3+2$ results in about a $100^{\circ}$ bend in the DNA. 3. Binding of GcvA to sites $3+2+1$ results in an apparent $12^{\circ}$ bend, possibly due to a GcvA-DNA looped complex whose mobility is relatively independent of the location of the GcvA sites. 4. Binding of GcvA to sites $3+2+1$ with a 4 bp change (AGTT) in site 1 away from consensus results in about an $80^{\circ}$ bend, possibly due to an inability of GcvA to bend DNA at site 1 to allow formation of a looped complex. 5 . Binding of GcvA to sites $3+2+1$ with an insertion of $2 \cdot 5$ turns of DNA in the intervening region between sites $3+2$ and site 1 results in a $25^{\circ}$ bend, possibly due to phasing the bend at sites $2+3$ and the bend at site 1 in opposite orientations such that the complex migrates as an apparent linear DNA-protein complex.

ducted using glycine-buffered gel electrophoresis systems (Jourdan \& Stauffer, 1999; Wonderling et al., 2000; Wilson et al., 1995). Since glycine acts as the coinducer with this LTTR controlled system, effects of the small molecule on the ability of GcvA to bind its specific sites in either the $g c v$ or $g c v A$ control region, or to mediate bending of the DNA when bound to these sites could not be examined under the assay conditions used. To determine whether glycine affects either of these properties of GcvA, GMS assays were done with purified GcvA in a non-glycine-based buffer.

Initially we tested whether GcvA binding alone induces a bend in DNA. DNA fragments carrying GcvA binding sites $3+2+1$ were cloned into the pBend 2 vector (see Methods), and five different restriction enzymes were used to generate DNA fragments of the same length, but with the GcvA binding sites at different positions relative to the centre of the fragments (Fig. 2). Gel electro- (a)

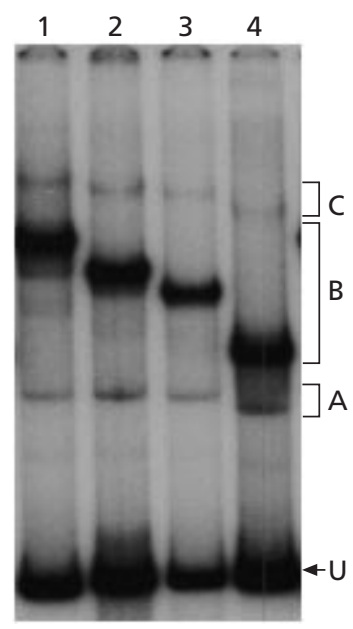

(b)

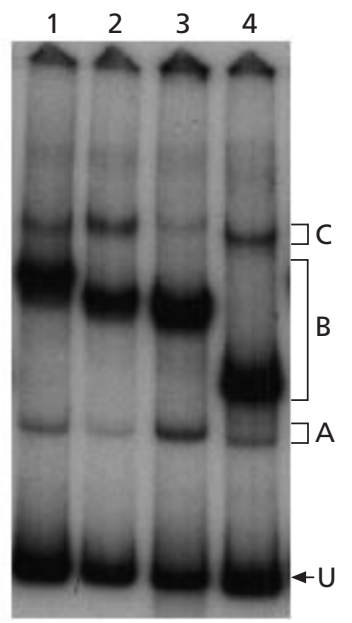

Fig. 5. GcvA binding to the $g c v$ control region with a $4 \mathrm{bp}$ change in binding site 1 (a) or a $25 \mathrm{bp}$ insertion between binding sites $3+2$ and site 1 (b). ${ }^{32}$ P-labelled DNA fragments of identical length were prepared with the GcvA binding sites at various locations (see Fig. 2). (a) Lanes: 1, Mlul fragment; 2, EcoRV fragment; 3, Stul fragment; 4, BamHI fragment. (b) Lanes: 1, Mlul fragment; 2, Xhol fragment; 3, EcoRV fragment; 4, BamHI fragment. GcvA was added at a dimer concentration of $20 \mathrm{nM}$. The positions of the unbound $(U)$, and three GcvA-retarded bands (A, B and C) are indicated. Measurements of mobilities for dark bands were from shorter exposures of the autoradiograms.

phoresis of the unbound fragments showed no significant intrinsic DNA bending (Fig. 3). The addition of GcvA resulted in three shifted bands. Although we did not perform DNase I footprinting on the shifted complexes, previous studies showed that the three GcvA binding sites have affinities for GcvA in the order 231 (Wilson et al., 1995). The different positions of the GcvA binding sites within the equal length fragments resulted in different relative mobilities of each of the three GcvA/DNA complexes (Fig. 3). The apparent bend angle was calculated for the $g c v$ control region using the formula $\mu M / \mu E=\cos \alpha / 2$, where $\mu M$ is the mobility of the DNA with the protein bound near the centre of the fragment and $\mu E$ is the mobility for the DNA fragment with the binding site located near the end of the DNA (Kim et al., 1989). When GcvA was bound to site 2 (band A in Fig. 3), a bend angle of about $30^{\circ}$ was calculated, when bound to sites $2+3$ (band B in Fig. 3) a bend angle of about $100^{\circ}$ was calculated, and when bound to all three sites (band C in Fig. 3), a bend angle of about $12^{\circ}$ was calculated. One explanation for the loss of bending when all three sites are occupied is that a GcvA-mediated loop forms, the mobility being relatively independent of the position of the binding sites within the loop (Fig. 4). Although other explanations are possible, we favour this interpretation based on results discussed below. When the GMS assay was performed on a DNA fragment carrying only GcvA site 1 , a bend angle of about $75^{\circ}$ was calculated (not shown). If phased with the bend induced at sites $3+2$, a looped structure is 
Table 2. GcvA-mediated activation of $g c v$ is independent of glycine

Cells were grown in GM medium with the indicated supplements and assayed for $\beta$-galactosidase activity (Miller, 1992). Each data point is the mean of two separate assays, each performed in triplicate. Standard deviations from the mean were less than $15 \%$ for all data presented.

\begin{tabular}{|c|c|c|c|}
\hline \multirow[t]{2}{*}{ Strain } & \multirow{2}{*}{$\begin{array}{l}\text { Relevant } \\
\text { genotype }\end{array}$} & \multicolumn{2}{|c|}{$\beta$-Galactosidase activity (Miller U) } \\
\hline & & $\mathrm{GM}+$ glycine & GM + Gly-Ser-Phe \\
\hline 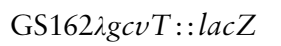 & WT & 963 & 295 \\
\hline GS1089igcvT::lacZ & glyA gcvR & 1061 & 1049 \\
\hline
\end{tabular}

possible. We also used a DNA fragment carrying the three GcvA binding sites but with a 4 bp change in site 1 that reduced the affinity of GcvA for site 1 about twofold and that resulted in a loss of GcvA-mediated repression (Wilson et al., 1995; Wonderling et al., 2000). The ability of GcvA to bind sites $2+3$ and bend the DNA were unchanged (Fig. 5a). However, when GcvA was bound to all three sites a bend angle of about $80^{\circ}$ was calculated. Thus, although the bp changes only resulted in a small decrease in the ability of GcvA to bind to site 1, they significantly altered GcvA-induced bending of the DNA. We also inserted 1.5 and 2.5 turns of DNA between site 1 and sites $2+3$. For both the +15 bp insert (not shown) and the +25 bp insert (Fig. 5b), GcvA binding to sites $2+3$ and its ability to bend DNA were essentially unchanged. However, when bound to all three sites, a bend angle of about $25^{\circ}$ was calculated. If the $75^{\circ}$ bend induced by GcvA bound to site 1 is phased opposite to the $100^{\circ}$ bend induced by GcvA bound to sites $3+2$, the data would be consistent with the bending pattern observed. The results are summarized in Fig. 4.

We then tested whether glycine effects the GcvA/DNA interaction. The addition of glycine $(3 \mathrm{mM})$ to the GMS assays did not show any alteration in either GcvA's binding affinity to the three sites in the control region, nor were there any changes in the calculated bend angles induced by GcvA binding to the DNA (data not shown).

\section{Does glycine directly affect GcvA-mediated expression of $g c v$ ?}

Since glycine does not significantly affect GcvA's ability to bind or bend DNA, we wanted to determine how glycine is involved in the activation mechanism. It was reported previously that mutations in $g c v R$ result in constitutive expression of the $g c v$ operon, but a reduced growth rate (Ghrist \& Stauffer, 1995). It is possible that the reduced growth rate is a result of glycine limitation due to its rapid catabolism by the GCV enzyme system. If true, this would suggest that activation of the $g c v$ operon could occur in the absence of glycine and would be consistent with the GMS assay results. Therefore, we tested whether the reduced growth rate in the $g c v R$ mutant strain GS1053 was due to altered glycine levels in the cell. The generation times of the WT strain GS162 grown in GM medium vs $\mathrm{GM}+$ glycine at $30^{\circ} \mathrm{C}$ are 85 and $84 \mathrm{~min}$, respectively, and for the $g c v R$ strain GS1053 are 130 and $84 \mathrm{~min}$, respectively. Thus, the $g c v R$ mutation results in glycine auxotrophy, but constitutive expression of $g c v$. Growth of the $g c v R$ strain in $\mathrm{GM}+$ inosine also reduced the generation time to 84 min. Since a glycine molecule is incorporated into the purine ring structure, the reduced generation time is possibly due to a sparing effect of glycine by purine supplementation.

We also constructed a $g l y A g c v R$ double mutant strain GS1089. This strain requires an exogenous source of glycine for growth due to the glyA mutation (Pizer, 1965). We used the Gly-Ser-Phe tripeptide to limit glycine (glycine concentration $50 \mu \mathrm{g} \mathrm{ml}^{-1}$ ). The generation time of the WT strain in GM+tripeptide at $30{ }^{\circ} \mathrm{C}$ was $82 \mathrm{~min}$ and the double mutant was more than $174 \mathrm{~min}$. The addition of glycine to the medium reduced the generation time of the mutant to that of the WT, suggesting that the double mutant is starved for glycine. In the WT lysogen, $g c v T$ : : lacZ expression was threefold lower in the presence of the tripeptide compared to glycine, suggesting that the concentration of glycine as tripeptide is limiting for activation (Table 2). In the gly $A$ $g c v R$ mutant lysogen, $g c v T$ : : lacZ expression was constitutive, although the cells were starved for glycine. These results and the results of the GMS assays suggest that glycine probably does not interact directly with GcvA to activate the $g c v$ operon.

\section{Glycine binds to GcvR}

If glycine does not affect GcvA's ability to bind or bend DNA, and the $g c v$ operon can be activated under glycine starvation conditions if $g c v R$ is inactivated, what is the role of glycine? We used micro-chamber equilibrium dialysis to determine where glycine fits into the regulatory mechanism. Purified $\operatorname{GcvA}_{6 \times h i s}$ at $25 \mu \mathrm{M}$ and purified native GcvR at $25 \mu \mathrm{M}$ were each dialysed against $250 \mu \mathrm{M}\left[{ }^{14} \mathrm{C}\right]$ glycine overnight at $20{ }^{\circ} \mathrm{C}$ (see Methods). $50 \mu$ l aliquots of 'outside' and 'inside' buffer were collected from each sample and the radioactivity measured as c.p.m. GcvA did not show a significant level of radioactivity as c.p.m. bound compared to a negative control (no protein 'inside'), indicating that glycine does not bind GcvA at the protein and ligand concentrations 


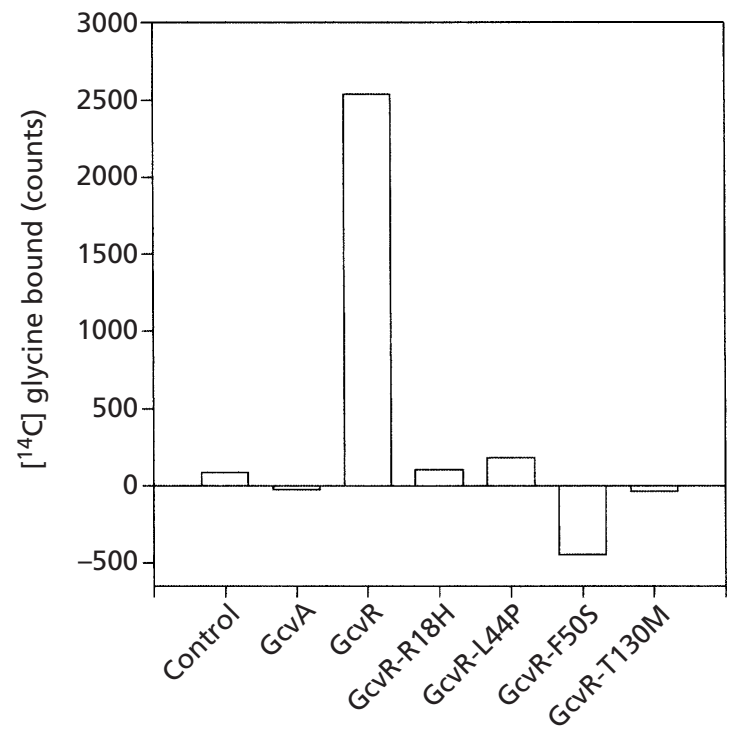

Fig. 6. Equilibrium dialysis experiments with $W T \operatorname{GcvA}_{6 \times h i s}, W T$ GcvR, mutant GcvRs and $\left[{ }^{14} \mathrm{C}\right]$ glycine. The designation after each mutant GcvR indicates the amino acid in the WT protein, its position, and the amino acid replacement. Approximately 16500 c.p.m. $\left[{ }^{14} \mathrm{C}\right]$ glycine were added to the 'outside' of each dialysis chamber, and counts of $\left[{ }^{14} \mathrm{C}\right]$ glycine bound to each protein were determined by subtracting the counts 'outside' from the counts 'inside' as described in Methods. Negative values for $\left[{ }^{14} \mathrm{C}\right]$ glycine bound by GcvA, GcvR-F50S and GcvRT130M are due to sampling errors which resulted in higher levels of activity being counted in the 'outside' samples for these alleles, resulting in negative values when subtracted from the levels counted for the 'inside' samples. The experiments were performed twice. Data shown are a representative set of values.

examined (Fig. 6). GcvR, in contrast, showed a high level of radioactivity as c.p.m. bound compared to the negative control and to GcvA (Fig. 6). Although this assay was conducted using a single protein and ligand concentration, the difference in ligand bound between GcvA and GcvR as compared to the 'no protein' control at the ligand and protein concentrations used suggests that glycine is likely bound by GcvR.

\section{Co-ppt of GcvA and GcvR}

Previous results suggested that a GcvA/GcvR complex is likely to form in vivo (Ghrist et al., 2001). Since the coinducer glycine binds GcvR rather than the activator GcvA, it is possible that glycine's role is to prevent a GcvA/GcvR interaction required for repression, permitting GcvA to function as an activator. We used a qualitative co-ppt assay to demonstrate in vitro that an interaction between GcvA and GcvR occurs and to determine whether glycine affects this interaction. Purified $\mathrm{GcvA}_{6 \times \text { his }}$ was bound to a $\mathrm{Ni}^{+}$-NTA agarose affinity matrix, followed by the addition of purified native GcvR. The matrix was washed with loading buffer to remove any unbound GcvR, and subsequently washed with loading buffer containing a low concentration of imidazole $(20 \mathrm{mM})$ to remove any nonspecific binding of

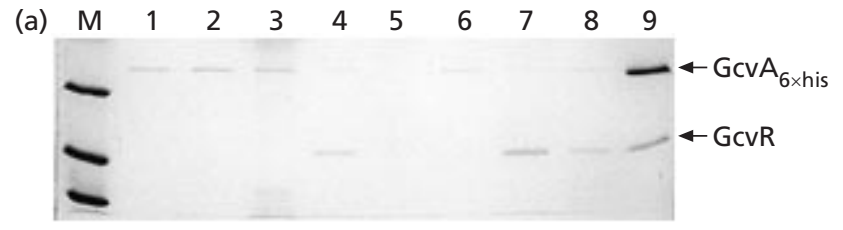

(b)

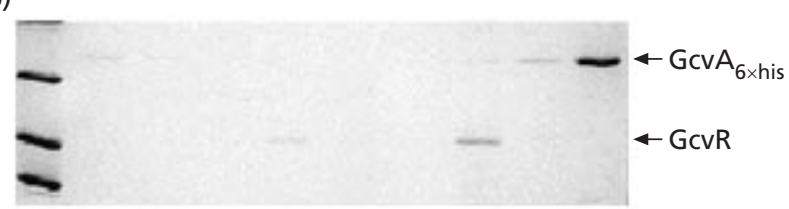

(c)

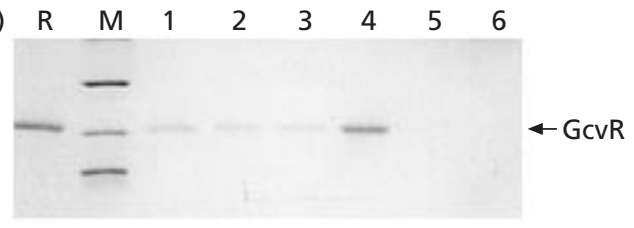

Fig. 7. Affinity co-ppt experiments of $\mathrm{GcvA}_{6 \times \text { his }}$ and $\mathrm{GcvR}$. Ni ${ }^{+}-$ NTA agarose matrix (Qiagen) was used to bind purified GcvA $_{6 \times h i s}$ followed by addition of purified GcvR to test for protein-protein interaction, observed as co-ppt of the two proteins. (a) Co-ppt fractions of GcvA $\mathrm{G}_{6 \times \text { his }}$ and GcvR. (b) Co-ppt fractions of $\mathrm{GcvA}_{6 \times \text { his }}$ and GcvR in the presence of $1 \mathrm{mM}$ glycine. (c) Co-ppt fractions of GcvR alone. (a) and (b), lanes 1-8 and (c), lanes $1-5$, show proteins eluted from the $\mathrm{Ni}^{+}$-NTA agarose matrix with loading buffer $C$ and wash buffer B. (a) and (b) lane 9 , and (c), lane 6 , show proteins that eluted from the affinity matrix with elution buffer ( $500 \mathrm{mM}$ imidazole). See Methods for details.

GcvR to the matrix. GcvA was then eluted from the matrix with buffer containing a high concentration of imidazole $(500 \mathrm{mM})$. The final elution of $\mathrm{GcvA}_{6 \times \text { his }}$ from the $\mathrm{Ni}^{+}$-NTA agarose affinity matrix also resulted in elution of a significant amount of GcvR (Fig. 7a, lane 9). When GcvR alone was incubated with the $\mathrm{Ni}^{+}-\mathrm{NTA}$ affinity matrix and subsequently washed with low imidazole $(20 \mathrm{mM})$, all of the GcvR was eluted from the affinity matrix, as no protein was eluted by the subsequent high imidazole wash (Fig. 7c, compare lanes 4 and 5 with lane 6). Thus, the GcvR co-eluting with GcvA (Fig. 7a, lane 9) was likely due to an interaction of GcvR with GcvA that allowed it to remain in complex with GcvA and the $\mathrm{Ni}^{+}$-NTA agarose affinity matrix until the high imidazole elution. When this experiment was performed in the presence of glycine $(1 \mathrm{mM})$ in the loading and elution buffers, all GcvR eluted either in the loading buffer or in the low concentration imidazole wash, and no longer eluted with GcvA (Fig. 7, compare panel a, lane 9 with panel b, lane 9). These results suggest that glycine disrupts a GcvA/GcvR interaction.

\section{GcvR proteins unable to bind glycine}

Previously, a point mutation in $g c v A$ was isolated that resulted in GcvA's inability to mediate full repression of a $g c v T:: l a c Z$ transcriptional fusion, but that did not alter GcvA's ability to function as an activator (Jourdan 
Table 3. Mutations in $g c v R$ that result in a loss of glycine-mediated activation of $g c v$

Cells were grown in GM medium with the indicated supplements and assayed for $\beta$-galactosidase activity [expressed in Miller units (Miller, 1992)]. Each data point is the mean of two separate assays, each performed in triplicate. Standard deviations from the mean were less than $15 \%$.

\begin{tabular}{|c|c|c|c|c|}
\hline \multirow[t]{2}{*}{ Strain/plasmid* } & \multirow{2}{*}{$\begin{array}{l}\text { Plasmid-encoded } \\
\qquad g c v R \text { allele }\end{array}$} & \multicolumn{3}{|c|}{$\beta$-Galactosidase activity } \\
\hline & & GM & GM+glycine & $\mathrm{GM}+$ inosine \\
\hline GS998גgcvT::lacZ & None & 78 & 91 & 42 \\
\hline GS1053igcvT::lacZ & None & 1393 & 1446 & 805 \\
\hline GS1053igcvT::lacZ[pGS338] & WT $g c v R$ & 209 & 1405 & 15 \\
\hline GS1053igcvT::lacZ[pGS558] & $g c v R \mathrm{R} 18 \mathrm{H}$ & 71 & 591 & 8 \\
\hline GS1053igcvT::lacZ[pGS559] & $g c v R L 44 \mathrm{P}$ & 82 & 595 & 8 \\
\hline GS1053igcvT::lacZ[pGS560] & gcvRF50S & 45 & 106 & 8 \\
\hline GS1053igcvT::lacZ[pGS589] & $g c v R T 130 \mathrm{M}$ & 64 & 584 & 7 \\
\hline
\end{tabular}

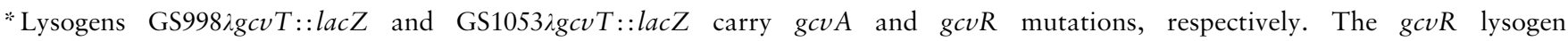
GS1053igcvT:: lacZ was transformed with a single-copy plasmid carrying either WT or mutant gcvR alleles.

\& Stauffer, 1998). The mutation resulted in an arginine to glycine change at residue 197 (R197G) and disrupted the GcvA/GcvR interaction as measured in a LexA twohybrid system (Ghrist et al., 2001). Our initial effort was to verify the GcvA/GcvR interaction. Convincing genetic evidence would be the isolation of allele-specific $g c v R$ mutations that restore the GcvA/GcvR interaction. The $g c v A$ strain GS998igcvT : lacZ carrying the gcvAR197G mutant allele on a single-copy plasmid (pGS311) was transformed with a multi-copy plasmid (pBR322) pool carrying PCR-induced random bp changes in $g c v R$ (see Methods). We assumed that transformants expressing mutant GcvR proteins that restore the interaction between GcvA-R197G and GcvR would produce either white or light blue colonies due to the ability of GcvR to repress expression of the $g c v T$ :: lacZ fusion. Four separate transformants with the correct phenotype were identified. Plasmid DNA was isolated from each transformant and the $g c v R$ sequence was determined. Three of the plasmids contained single bp mutations resulting in amino acid changes R18H, L44P and T130M. The fourth clone contained two bp changes, one silent and the other resulting in the amino acid change F50S. The WT and mutant $g c v R$ alleles were cloned into the single-copy plasmid pGS311 in tandem with the mutant gcvAR197G allele. The plasmids were then used to transform the $g c v A$ gcvR strain GS1054igcv T::lacZ to determine the effects of the mutations on regulation of the $g c v$ operon when the WT and mutant GcvR proteins were at more physiological concentrations. Unexpectedly, when both gcvAR197G and the individual mutant gcvR alleles were expressed from the single-copy plasmid, none of the $g c v R$ mutants had any suppressor effect on $g c v T:$ : lac $Z$ expression when compared to the WT $g c v R$ allele (data not shown). Since the four $g c v R$ mutations result in amino acid changes at different positions in GcvR, we hypothesized that the mutations might have altered GcvR to make it a more efficient repressor. Thus, when expressed from a multicopy plasmid, the mutant GcvR proteins are able to interact with GcvA-R197G to cause repression, but not when expressed from the single-copy plasmid. If this hypothesis is correct, then the mutations might have an effect on WT GcvA expressed from a single chromosomal $g c v A$ gene even though they did not have an effect when GcvA-R197G was expressed from the single-copy plasmid. We tested this hypothesis by measuring the effects of the $g c v R$ mutant alleles in the presence of a single copy of the WT gcvA gene. As controls, we used the gcvA mutant GS998igcvT::lacZ to show basal levels of expression in the absence of the activator protein and the $g c v R$ mutant GS1053igcvT::lacZ to show constitutive levels in the absence of GcvR. The gcvA mutant GS998igcvT : : lacZ is neither activated in the presence of glycine nor repressed in the presence of inosine, except for a twofold PurR-mediated repression (Wilson et al., 1993a), whereas the $g c v R$ mutant GS1053igcvT::lacZ shows constitutive expression, except for the twofold PurRmediated repression (Table 3). The WT and mutant $g c v R$ alleles were cloned into the single copy plasmid pGS311 alone. The plasmids were then used to transform the $g c v R$ strain GS1053igcv T::lacZ to determine the effects of the mutants in the presence of the single copy of the WT gcvA allele on the chromosome. In GM medium, the single-copy plasmid carrying either the $g c v R R 18 \mathrm{H}, g c v R L 44 \mathrm{P}$ or $g c v R T 130 \mathrm{M}$ allele resulted in a 17 - to 22 -fold reduction in $\beta$-galactosidase levels compared to a sevenfold reduction by the WT $g c v R$; in $\mathrm{GM}+$ glycine there was a $2 \cdot 5$-fold reduction in $\beta$ galactosidase levels compared to no significant reduction by the WT $g c v R$; and in GM + inosine, there was a 101to 115 -fold reduction in $\beta$-galactosidase levels compared to a 54-fold reduction for WT gcvR (Table 3). The effects of the $g c v R F 50 S$ allele were more severe, resulting in a 31-fold reduction in GM, a 14-fold reduction in $\mathrm{GM}+$ glycine and a 101-fold reduction in GM + inosine (Table 3). 
One possible cause for the phenotypes seen in the $g c v R$ mutants could be that the mutated GcvR proteins are reduced in their ability to bind glycine. To test this hypothesis, the GcvR-R18H, GcvR-L44P, GcvR-F50S and GcvR-T130M proteins were purified and the mutant proteins $(25 \mu \mathrm{M})$ dialysed against $\left[{ }^{14} \mathrm{C}\right]$ glycine $(250 \mu \mathrm{M})$. No significant accumulation of label across the membrane was seen with any of the mutant proteins at the protein and ligand concentrations used as compared to the WT GcvR protein (Fig. 6).

\section{DISCUSSION}

Most characterized LTTR proteins require small coeffector molecules to carry out their regulatory functions (Schell, 1993). These low molecular mass co-effectors are believed to directly bind their respective LTTR proteins, resulting in altered binding site affinity or relaxed DNA bending by the LTTR proteins at the regulated promoters (Schell, 1993). These changes are necessary for appropriate transcriptional regulation (Gao \& Gussin, 1991; Wek \& Hatfield, 1988; Ogawa et al., 1999; Rhee et al., 1998; van Keulen et al., 1998). The addition of glycine to GM medium results in GcvAmediated activation of the $g c v$ operon (Plamann et al., 1983). However, several lines of evidence suggest that the co-inducer effect of glycine might not occur directly through GcvA. First, although GcvA demonstrates a preferential binding to its three sites in the $g c v$ control region (2 3 1), glycine did not affect the order in which the three sites were filled or the apparent affinity for the sites (Wilson et al., 1995). Second, GcvA induces constitutive expression of a $g c v T:: l a c Z$ fusion in the absence of glycine if GcvR is inactivated, a growth condition that results in a partial glycine auxotrophy (Table 2; Ghrist \& Stauffer, 1995). The GMS assays in this study are consistent with this hypothesis. GcvA bound to the $g c v$ promoter region and induced a bend in the DNA in the absence of glycine (Fig. 3). The addition of $3 \mathrm{mM}$ glycine, however, had no significant affect on either the affinity of GcvA binding for its target sites or the degree of DNA bending.

Since glycine did not alter GcvA's ability to bind or bend gcv DNA, and since GcvR is required for GcvA to mediate negative regulation of the $g c v$ operon, as well as for GcvA to show a positive response to glycine (Ghrist \& Stauffer, 1995), it seemed possible that glycine might interact with GcvR rather than GcvA. We tested this possibility by equilibrium dialysis. The results showed that glycine binds GcvR rather than GcvA (Fig. 6), suggesting that the co-activator glycine functions by a different mechanism for $g c v$ control compared to the coactivators for other LTTR-regulated operons. Results from in vivo studies using a LexA two-hybrid system suggested that a direct interaction occurs between GcvA and GcvR (Ghrist et al., 2001). The in vitro results from this study showed that when $\mathrm{GcvA}_{6 \times \text { his }}$ was bound to $\mathrm{Ni}^{+}$-NTA agarose affinity matrix, followed by addition of WT GcvR, a significant amount of GcvR co-eluted with GcvA during a high imidazole wash (Fig. 7a).

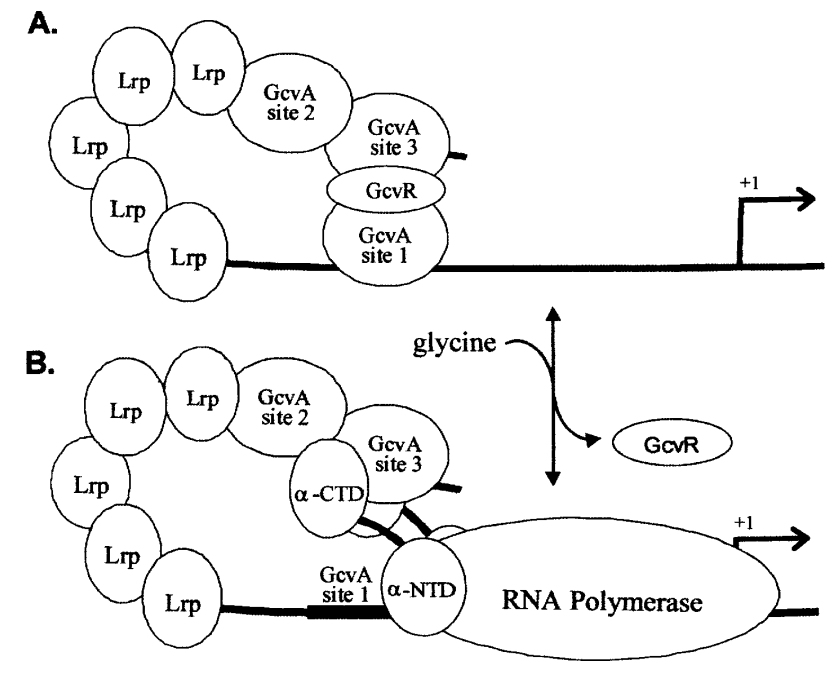

Fig. 8. Model for repression and activation of the gcv operon. $A$. In the absence of glycine, GcvR binds directly to GcvA, forming a repression complex. Whether this prevents RNAP binding to the promoter, or prevents a GcvA/RNAP contact necessary for activation, is unknown. B. In the presence of glycine, a GcvA/GcvR interaction is blocked. Bending of the DNA by Lrp and GcvA allows GcvA bound to sites $3+2$ to interact with the $\alpha$-carboxy-terminal domain of RNA polymerase, permitting stimulation of RNAP, and activation of transcription. Whether it is GcvA bound to site 3 or site 2 that contacts RNAP is unknown. Although GcvA binding site 1 overlaps the RNAP binding region, site 1 is only required for GcvA-mediated repression of the operon (Wilson et al., 1995; Wonderling et al., 2000).

Furthermore, the addition of glycine $(1 \mathrm{mM})$ to the loading and wash buffers inhibited this interaction (Fig. $7 \mathrm{~b})$. These results are consistent with a direct GcvA/ GcvR interaction and suggest that the role of the coinducer glycine is either to block this association or to cause a dissociation of the complex once formed. The isolation of $g c v R$ mutants that encode proteins with reduced abilities to bind glycine and that result in a reduced ability of glycine to activate gcvT::lacZ expression is consistent with this model. We used purified GcvR in a GMS assay with gcv DNA and in both the absence and presence of glycine. However, we could not show any binding of GcvR to $g c v$ DNA (data not shown). These results suggests that GcvR interacts directly with GcvA to form a repression complex: a somewhat unconventional mechanism for prokaryotes (Fig. 8A).

The above model predicts that transcription of the $g c v$ operon is inversely proportional to the level of GcvA/ GcvR complex formed, which in turn, is inversely proportional to the level of glycine present in the cell. Thus, glycine does not act as a classical co-activator in this system, but rather through a mechanism of derepression by binding to GcvR and preventing GcvR from interacting with GcvA to block GcvA's activator function. In mid-exponential phase cells growing in GM medium it was determined that the intracellular con- 
centration of glycine is approximately $41 \mu \mathrm{M}$ (Raunio \& Rosenqvist, 1970). This level is apparently insufficient to allow full de-repression of the $g c v$ operon as seen in the $g c v R$ mutant GS1053igcv T::lacZ, but is sufficient to bind some GcvR and to allow de-repression above the basal level seen in the gcvA mutant GS998igcvT::lacZ. As the intracellular glycine concentration increases due to transport of exogenous glycine, more GcvR is bound by glycine, resulting in a further loss of repression and increased activation of $g c v T:: l a c Z$. Of interest, the GcvR-R18H, GcvR-L44P, GcvR-F50S and GcvRT130M proteins did not bind glycine in the equilibrium dialysis experiment, but did show some response to glycine in vivo (Fig. 6 and Table 3). If glycine binds to GcvR in a concentration-dependent manner to disrupt the GcvA/GcvR complex, then the GcvR mutant proteins likely still bind glycine, but with reduced affinity. Additional equilibrium dialysis experiments at different GcvR and ligand concentrations will be necessary to verify this hypothesis.

It is worth noting that full repression of the $g c v$ operon requires the addition of purines to GM medium (Wilson et al., 1993a; Ghrist \& Stauffer, 1995). Although the mechanism of purine involvement is unknown, purines could either enhance the interaction between GcvA and GcvR, forming a more stable repressor complex, or change the conformation of the repressor complex at the promoter to prevent transcriptional initiation by RNAP. Furthermore, the addition of both glycine and purines to the growth medium results in derepression of the $g c v$ operon (Stauffer \& Stauffer, 1994; Wilson et al., 1993a). The dominance of glycine to purines in the regulatory mechanism, and the ability of glycine to disrupt the GcvA/GcvR interaction are consistent with a GcvA/ GcvR complex being necessary for purine-mediated repression. Since all three GcvA binding sites are required for normal repression of the $g c v$ operon (Wilson et al., 1995; Wonderling et al., 2000), it is likely that GcvA and GcvR form a repression loop (Fig. 8A). DNA looping normally occurs between identical proteins (Gralla \& Collado-Vides, 1996). Verification of this as a heterologous protein system for DNA looping will provide a novel perspective into the basic mechanism by which protein/protein interactions control gene expression.

Previously it was shown that specific amino acid residues in the $\alpha$-subunit of RNAP ( $\alpha$-carboxy-terminal domain), when mutated, disrupt GcvA-mediated activation of the gcv operon, but not GcvA-mediated repression (Jourdan $\&$ Stauffer, 1999). In addition, positive control mutants were isolated in $g c v A$ that decreased GcvA's ability to activate $g c v$ transcription, but that did not affect DNA binding or GcvA-mediated repression (Jourdan \& Stauffer, 1998). Since GcvA-mediated activation requires GcvA bound to sites 2 and 3, located 214-271 bp upstream of the transcription start site, it is reasonable to assume that a looped nucleoprotein structure is required for an appropriate GcvA/RNAP contact for activation (Fig. 8B). Although the results of this study show that GcvA also induces a bend in the DNA, it is not known whether the GcvA-induced DNA bending plays a direct role in GcvA-mediated regulation of the $g c v$ operon.

\section{ACKNOWLEDGEMENTS}

This work was supported in part by grant MCB 01-01918 from the National Science Foundation

\section{REFERENCES}

Berlyn, M. K. B., Low, K. B. \& Rudd, K. E. (1996). Linkage map of Escherichia coli K-12. In Escherichia coli and Salmonella: Cellular and Molecular Biology, pp. 1715-1902. Edited by F. C. Neidhardt and others. Washington, DC: American Society for Microbiology.

Blakely, R. L. (1969). The Biochemistry of Folic acid and Related Pteridines. Amsterdam: Elsevier.

Calvo, J. M. \& Matthews, R. G. (1994). The leucine-responsive regulatory protein, a global regulator of metabolism in Escherichia coli. Microbiol Rev 58, 466-490.

Colyer, T. E. \& Kredich, N. M. (1996). In vitro characterization of constitutive CysB proteins from Salmonella typhimurium. Mol Microbiol 21, 247-256.

Fried, M. \& Crothers, D. M. (1981). Equilibria and kinetics of $l a c$ repressor-operator interactions by polyacrylamide gel electrophoresis. Nucleic Acids Res 9, 6505-6525.

Gao, J. \& Gussin, G. N. (1991). Mutations in TrpI binding site II that differentially affect activation of the $\operatorname{trp} B A$ promoter of Pseudomonas aeruginosa. EMBO J 10, 4137-4144.

Garner, M. M. \& Revzin, A. (1981). A gel electrophoresis method for quantifying the binding of proteins to specific DNA regions: applications to components of the Escherichia coli lactose operon regulatory system. Nucleic Acids Res 9, 3047-3060.

Ghrist, A. C. \& Stauffer, G. V. (1995). Characterization of the Escherichia coli gcvR gene encoding a negative regulator of $g c v$ expression. J Bacteriol 177, 4980-4984.

Ghrist, A. C., Heil, G. \& Stauffer, G. V. (2001). GcvR interacts with GcvA to inhibit activation of the Escherichia coli glycine cleavage operon. Microbiology 147, 2215-2221.

Gralla, J. D. \& Collado-Vides, J. (1996). Organization and function of transcription regulatory elements. In Escherichia coli and Salmonella: Cellular and Molecular Biology, pp. 1232-1245. Edited by F. C. Neidhardt and others. Washington, DC: American Society of Microbiology.

Hryniewicz, M. N. \& Kredich, N. M. (1994). Stoichiometry of binding of CysB to the cysJIH, cysK, and cysP promoter regions of Salmonella typhimurium. J Bacteriol 176, 3673-3682.

Jordan, P. M. \& Sheman, D. (1972). $\delta$-Aminolevulinic acid synthesis. In The Enzymes, vol. 7, pp. 339-356. Edited by P. D. Boyer. New York: Academic Press.

Jørgensen, C. \& Dandanell, G. (1999). Isolation and characterization of mutations in the Escherichia coli regulatory protein XapR. J Bacteriol 181, 4397-4403.

Jourdan, A. D. \& Stauffer, G. V. (1998). Mutational analysis of the transcriptional regulator GcvA: amino acids important for activation, repression, and DNA binding. J Bacteriol 180, 4865-4871.

Jourdan, A. D. \& Stauffer, G. V. (1999). GcvA-mediated activation of $g c v T$-lacZ expression involves the carboxy-terminal domain of the $\alpha$ subunit of RNA polymerase. FEMS Microbiol Lett 181, $307-312$. 
Kikuchi, G. (1973). The glycine cleavage system: composition, reaction mechanism, and physiological significance. Mol Cell Biochem 1, 169-187.

Kilstrup, M., Meng, L. M., Neuhard, J. \& Nygaard, P. (1989). Genetic evidence for a repressor of synthesis of cytosine deaminase and purine biosynthesis enzymes in Escherichia coli. J Bacteriol 171, 2124-2127.

Kim, J., Zwieb, C., Wu, C. \& Adhya, S. (1989). Bending of DNA by gene-regulatory proteins : construction and use of a DNA bending vector. Gene 85, 15-23.

Lin, R., D'Ari, R. \& Newman, E. B. (1992). $\lambda$ placMu insertions in genes of the leucine regulon: extension of the regulon to genes not regulated by leucine. J Bacteriol 174, 1948-1955.

Marinus, M. G. (1996). Methylation of DNA. In Escherichia coli and Salmonella: Cellular and Molecular Biology, pp. 782-791. Edited by F. C. Neidhardt and others. Washington, DC: American Society of Microbiology.

Matthews, R. G. (1996). One-carbon metabolism. In Escherichia coli and Salmonella: Cellular and Molecular Biology, pp. 600-611. Edited by F. C. Neidhardt and others. Washington, DC: American Society of Microbiology.

Miller, J. H. (1992). A Short Course in Bacterial Genetics. Cold Spring Harbor, NY: Cold Spring Harbor Laboratory.

Mudd, S. H. \& Cantoni, G. L. (1964). Biological transmethylation, methyl-group neogenesis and other 'one-carbon' metabolic reactions dependent upon tetrahydrofolic acid. In Comprehensive Biochemistry, vol. 15, pp. 1-47. Edited by M. Florkin \& E. H. Stotz. Amsterdam: Elsevier.

Ogawa, N., McFall, S. M., Klem, T. J., Miyashita, K. \& Chakrabarty, A. M. (1999). Transcriptional activation of the chlorocatecol degradative genes of Ralstonia eutropha NH9. J Bacteriol 181, 6697-6705.

Pizer, L. I. (1965). Glycine synthesis and metabolism in Escherichia coli. J Bacteriol 89, 1145-1150.

Pizer, L. I. \& Potochny, M. L. (1964). Nutritional and regulatory aspects of serine metabolism in Escherichia coli. J Bacteriol 88, 611-619.

Plamann, M. D., Rapp, W. D. \& Stauffer, G. V. (1983). Escherichia coli $\mathrm{K} 12$ mutants defective in the glycine cleavage enzyme system. Mol Gen Genet 192, 15-20.

Raunio, R. \& Rosenqvist, H. (1970). Amino acid pool of Escherichia coli during the different phases of growth. Acta Chemica Scandinavica 24, 2737-2744.

Rhee, K. Y., Senear, D. F. \& Hatfield, G. W. (1998). Activation of gene expression by a ligand-induced conformational change of a protein-DNA complex. J Biol Chem 273, 11257-11266.

Rolfes, R. J. \& Zalkin, H. (1988). Escherichia coli gene purR encoding a repressor protein for purine nucleotide synthesis. $J$ Biol Chem 263, 19653-19661.

Sambrook, J., Fritsch, E. F. \& Maniatis, T. (1989). Molecular Cloning: a Laboratory Manual, 2nd edn. Cold Spring Harbor, NY : Cold Spring Harbor Laboratory.

Schell, M. A. (1993). Molecular biology of the LysR family of transcriptional regulators. Annu Rev Microbiol 47, 597-626.

Stauffer, G. V. (1996). Biosynthesis of serine, glycine, and onecarbon units. In Escherichia coli and Salmonella: Cellular and Molecular Biology, pp. 506-513. Edited by F. C. Neidhardt and others. Washington, DC: American Society of Microbiology.
Stauffer, L. T. \& Stauffer, G. V. (1994). Characterization of the gcv control region from Escherichia coli. J Bacteriol 176, 6159-6164.

Stauffer, L. T. \& Stauffer, G. V. (1998a). Spacing and orientation requirements of GcvA-binding sites 3 and 2 and the Lrpbinding region for gcvT: lacZ expression in Escherichia coli. Microbiology 144, 1417-1422.

Stauffer, L. T. \& Stauffer, G. V. (1998b). Roles for GcvA-binding sites 3 and 2 and the Lrp-binding region in $g c v T::$ lacZ expression in Escherichia coli. Microbiology 144, 2865-2872.

Stauffer, L. T. \& Stauffer, G. V. (1999). Role for the leucineresponsive regulatory protein (Lrp) as a structural protein in regulating the Escherichia coli gcvTHP operon. Microbiology 145, 569-576.

Stauffer, L. T., Ghrist, A. \& Stauffer, G. V. (1993). The Escherichia coli gcvT gene encoding the T-protein of the glycine cleavage enzyme system. DNA seq-J DNA Seq Mapping 3, 339-346.

Stauffer, L. T., Fogarty, S. J. \& Stauffer, G. V. (1994). Characterization of the Escherichia coli gcv operon. Gene 142, 17-22.

Steiert, P. S., Stauffer, L. T. \& Stauffer, G. V. (1990). The $l p d$ gene product functions as the $\mathrm{L}$ protein in the Escherichia coli glycine cleavage enzyme system. J Bacteriol 172, 6142-6144.

van Keulen, G., Girbal, L., van der Bergh, E. R. E., Dijkhuizen, L. \& Meijer, W. G. (1998). The LysR-type transcriptional regulator CbbR controlling autotrophic $\mathrm{CO}_{2}$ fixation by Xanthobacter flavus is an NADPH sensor. J Bacteriol 180, 1411-1417.

Vogel, H. J. \& Bonner, D. M. (1956). Acetylornithinase of Escherichia coli: partial purification and some properties. J Biol Chem 218, 97-106.

Wang, L., Helmann, J. D. \& Winans, S. C. (1992). The $A$. tumefaciens transcriptional activator OccR causes a bend at a target promoter, which is partially relaxed by a plant tumor metabolite. Cell 69, 659-667.

Wek, R. C. \& Hatfield, G. W. (1988). Transcriptional activation at adjacent operators in the divergent-overlapping ilv $\mathrm{Y}$ and $i l v \mathrm{C}$ promoters of Escherichia coli. J Mol Biol 203, 643-663.

Wilson, R. L. \& Stauffer, G. V. (1994). DNA sequence and characterization of GcvA, a LysR family regulatory protein for the Escherichia coli glycine cleavage enzyme system. J Bacteriol 176, 2862-2868.

Wilson, R. L., Stauffer, L. T. \& Stauffer, G. V. (1993a). Roles of GcvA and PurR proteins in negative regulation of the Escherichia coli glycine cleavage enzyme system. J Bacteriol 175, 5129-5134.

Wilson, R. L., Steiert, P. S. \& Stauffer, G. V. (1993b). Positive regulation of the Escherichia coli glycine cleavage enzyme system. J Bacteriol 175, 902-904.

Wilson, R. L., Urbanowski, M. L. \& Stauffer, G. V. (1995). DNA binding sites of the LysR-type regulator GcvA in the $g c v$ and $g c v A$ control regions of Escherichia coli. J Bacteriol 177, 4940-4946.

Wonderling, L. D. \& Stauffer, G. V. (1999). The cyclic AMP receptor protein is dependent on GcvA for regulation of the $g c v$ operon. J Bacteriol 181, 1912-1919.

Wonderling, L. D., Urbanowski, M. L. \& Stauffer, G. V. (2000). GcvA biding site 1 in the gcvTHP promoter of Escherichia coli is required for GcvA-mediated repression but not for GcvAmediated activation. Microbiology 146, 2909-2918.

Zhou, Y., Zhang, X. \& Ebright, R. H. (1991). Random mutagenesis of gene-sized DNA molecules by use of PCR with Taq DNA polymerase. Nucleic Acids Res 19, 6052.

Received 9 January 2002; revised 19 March 2002; accepted 2 April 2002. 